\title{
The antimicrobial activity of lapachol and its thiosemicarbazone and semicarbazone derivatives
}

\author{
Marina Azevêdo Souza', Susana Johann ${ }^{1,2} /{ }^{+}$, Luciana Alves Rodrigues dos Santos Lima ${ }^{3}$, \\ Fernanda Fraga Campos ${ }^{1,2}$, Isolda Castro Mendes ${ }^{4}$, Heloisa Beraldo ${ }^{5}$, \\ Elaine Maria de Souza-Fagundes ${ }^{6}$, Patrícia Silva Cisalpino² ${ }^{2}$, Carlos Augusto Rosa ${ }^{2}$ \\ Tânia Maria de Almeida Alves ${ }^{1}$, Nívea Pereira de Sá ${ }^{2}$ Carlos Leomar Zani'
}

\footnotetext{
${ }^{1}$ Laboratório de Química de Produtos Naturais, Centro de Pesquisas René Rachou-Fiocruz, Belo Horizonte, MG, Brasil ${ }^{2}$ Departamento de Microbiologia ${ }^{6}$ Departamento de Fisiologia e Biofísica, Instituto de Ciências Biológicas ${ }^{4}$ Escola de Belas Artes ${ }^{5}$ Departamento de Química, Instituto de Ciências Exatas, Universidade Federal de Minas Gerais, Belo Horizonte, MG, Brasil ${ }^{3}$ Universidade Federal de São João Del Rei, Campus Centro Oeste Dona Lindu, Divinópolis, MG, Brasil
}

Lapachol was chemically modified to obtain its thiosemicarbazone and semicarbazone derivatives. These compounds were tested for antimicrobial activity against several bacteria and fungi by the broth microdilution meth$o d$. The thiosemicarbazone and semicarbazone derivatives of lapachol exhibited antimicrobial activity against the bacteria Enterococcus faecalis and Staphylococcus aureus with minimal inhibitory concentrations (MICs) of 0.05 and $0.10 \mu \mathrm{mol} / \mathrm{mL}$, respectively. The thiosemicarbazone and semicarbazone derivatives were also active against the pathogenic yeast Cryptococcus gattii (MICs of 0.10 and $0.20 \mu \mathrm{mol} / \mathrm{mL}$, respectively). In addition, the lapachol thiosemicarbazone derivative was active against 11 clinical isolates of Paracoccidioides brasiliensis, with MICs ranging from 0.01-0.10 $\mu \mathrm{mol} / \mathrm{mL}$. The lapachol-derived thiosemicarbazone was not cytotoxic to normal cells at the concentrations that were active against fungi and bacteria. We synthesised, for the first time, thiosemicarbazone and semicarbazone derivatives of lapachol. The MICs for the lapachol-derived thiosemicarbazone against $\mathrm{S}$. aureus, E. faecalis, C. gattii and several isolates of P. brasiliensis indicated that this compound has the potential to be developed into novel drugs to treat infections caused these microbes.

Key words: antimicrobial agents - lapachol - Paracoccidioides

Lapachol (2-hydroxy-3-(3-methylbut-2-enyl)naphthalene-1,4-dione) is a natural pigment that was originally isolated from species of the Bignoniaceae family, but is also found in other plant families (Araújo et al. 2002, Fonseca et al. 2003). This naphthoquinone exhibits interesting antimicrobial, antitumor, antiplasmodial, antioxidant and trypanocidal properties (Araújo et al. 2002). There are many literature reports on lapachol derivatives. However, the thiosemicarbazone and semicarbazone derivatives of lapachol have never been studied. Thiosemicarbazones and semicarbazones from sources other than lapachol, such as isatin thiosemicarbazone and benzaldehyde semicarbazone, have been widely studied and are known to have extensive pharmacological profiles, e.g., antimicrobial and anticonvulsant activities (Beraldo 2004, Vieira et al. 2010).

In this study, we searched for novel lapachol derivatives with greater activity and lower toxicity for the treatment of infectious diseases. Treating infectious diseases that are caused by bacteria or fungi remains an important and challenging public health problem (Jones et

Financial support: FIOCRUZ, CNPq, CAPES, FAPEMIG, INCTINOFAR

+Corresponding author: susjohann@yahoo.com.br

Received 27 June 2012

Accepted 19 September 2012 al. 2008). Although substantial advances in biomedical science and public health have facilitated the control of numerous infectious diseases over the past century, the world has witnessed an increasing incidence and geographical expansion of emerging and re-emerging infectious diseases (Jones et al. 2008, Yang et al. 2012). Discovering new antimicrobial agents is important because several pathogenic microorganisms have acquired resistance. The prevalence of Staphylococcus aureus strains that are resistant to conventional antibiotics has greatly increased in some hospitals (Fluit et al. 2001, Hidron et al. 2008, Rosenthal et al. 2010).

There has been an increase in the number of immunocompromised hosts because of advances in medical technology and the human immunodeficiency virus pandemic (Wills et al. 2000) and the risk for opportunistic fungal infections has greatly increased in these patients. Moreover, common pathogens and new pathogenic species that possess intrinsic primary resistance are rapidly developing secondary resistance to the current antifungal agents (White et al. 1998). Other diseases, such as paracoccidioidomycosis (PCM), require long-term therapy to ensure a good clinical response and to avoid a relapse. Importantly, long periods of treatment, which are typically required to control these types of fungal infections, are correlated with drug toxicity, high costs and treatment abandonment by the patients. Relapse is a significant obstacle for patients and those patients who do not respond and severely ill patients pose a problem for conventional therapeutic approaches (Brummer et al. 1993, Coutinho 
et al. 2002, Paniago et al. 2003, Travassos et al. 2008). The increase in antibacterial resistance and the restricted number of commercially available antifungal drugs emphasise the need for the development of novel and more effective antifungal and antibacterial agents.

In this work, we evaluated the antimicrobial activity of the thiosemicarbazone and semicarbazone derivatives of lapachol, which we synthesised for the first time, and tested against several clinically important microorganisms. Lapachol was also tested. Lapachol and its thiosemicarbazone derivative were also tested against human peripheral blood mononuclear cells (PBMCs).

\section{SUBJECTS, MATERIALS AND METHODS}

Synthesis - Lapachol was isolated from Tabebuia ochracea in a previous study by Zani et al. (1991). Thiosemicarbazide (Sigma-Aldrich, Steinheim, Germany) was purified by crystallisation from water. Acetone (Vetec, RJ, Brazil), methanol (Sigma-Aldrich), semicarbazide hydrochloride (Sigma-Aldrich) and sodium hydroxide (Sigma-Aldrich, Steinheim, Germany) were used without further purification. Column chromatography was performed using silica gel 60G (70-230 mesh). Thin-layer chromatography (TLC) was executed on precoated TLC silica gel $60 \mathrm{~F}_{254}$ plates Merck (Darmstadt, Germany) and the spots were visualised under ultraviolet (UV) light at wavelengths of 254 and $366 \mathrm{~nm}$ after the plates had been sprayed with vanillin- $\mathrm{H}_{2} \mathrm{SO}_{4}$ and heated at $120^{\circ} \mathrm{C}$ for $10 \mathrm{~min}$. Analytical high-pressure liquid chromatography (Shim-Pak prep SiL, $4 \mu \mathrm{m}, 4.6 \mathrm{x}$ $250 \mathrm{~mm}, 1 \mathrm{~mL} / \mathrm{min}$ ) was performed on a Shimadzu chromatography system equipped with an LC10AD pump and a UV detector set at $\lambda_{210} \mathrm{~nm}$ and $\lambda_{240} \mathrm{~nm}$. Nuclear magnetic resonance (NMR) spectra were obtained on a Bruker DRX 400 spectrometer at $400 \mathrm{MHz}$ using tetramethylsilane as an internal standard. Mass spectrometry (MS) results were acquired on a Thermo Finnigan LCQAdvantage spectrometer equipped with an electrospray ion (ESI) source. Solutions of the compounds at $200 \mu \mathrm{g} /$ $\mathrm{mL}$ in 1:1 $\mathrm{MeOH}-\mathrm{H}_{2} \mathrm{O}$ were infused at a rate of 0.025 $\mathrm{mL} / \mathrm{min}$ and positive and negative mass spectra were acquired with an $\mathrm{m} / \mathrm{z}$ range of 50-1,000 daltons. The cone voltages were optimised for positive and negative ion analysis between $25-50 \mathrm{~V}$. The capillary voltage was set at $4.5 \mathrm{kV}$ in positive ion mode and $23.1 \mathrm{kV}$ in negative ion mode. For the MS/MS experiments, the parent ion isolation width was 3.8 daltons and the normalised collision energy was set at $30 \%$ for both compounds. Fifty scans from 150-600 daltons were collected to generate the averaged spectra.

The X-ray diffraction data were collected on an Oxford-Diffraction GEMINI diffractometer (LabCri) using a graphite-enhanced MoKa radiation source $(\mathrm{k}=$ $0.71069 \AA$ ) at 293(2) K. The lapachol thiosemicarbazone twin crystal was mounted on a glass fibre and examined by structural X-ray diffraction methods. The data collection, integration and scaling of the reflections were performed with the CrysAlis suite programs (CrysAlis RED, Oxford Diffraction Ltd, version 1.171.32.38 and SCALE3 ABSPACK Scaling Algorithm, CrysAlis RED, Oxford Diffraction Ltd, version 1.171.32.38).
The final unit cell parameters were determined by fitting all the reflections. The structures were solved by direct methods with the program SHELXS-97 (Sheldrick 1997) and were refined by full-matrix least-squares methods against $\mathrm{F}^{2}$ using SHELXL-97 (Sheldrick 1997). The positional and anisotropic atomic displacement parameters of the compound were refined for non-hydrogen atoms. Although all the hydrogen atoms could be identified in a Fourier difference map in the final model, the hydrogen atoms of lapachol thiosemicarbazone were included in the molecular model at stereo-chemical positions and were refined with the riding method. The molecular graphic was obtained from ORTEP (Johnson 1965, Farrugia 1997, Farrugia \& Win 1999). The studied material was endotoxin free.

Synthesis of lapachol thiosemicarbazone - A suspension of $10 \mathrm{mmol}$ lapachol in $100 \mathrm{~mL}$ of water was added to $100 \mathrm{~mL}$ of $0.1 \mathrm{M} \mathrm{NaOH}$, yielding a dark red solution. An aqueous-methanolic $(50 \%)$ solution of thiosemicarbazide ( $12 \mathrm{mmol}$ ) was added dropwise to the above solution with constant stirring. The mixture was stirred for approximately $21 \mathrm{~h}$, after which time the solution was neutralised with $10 \% \mathrm{HCl}$. The crude precipitated product was filtered and washed with cold water. The resulting solid was recrystallised from methanol and acetone (1:1), giving an orange crystalline thiosemicarbazone with a yield of $73 \%$ (Chikate et al. 2005). The lapachol thiosemicarbazone was analysed by melting point analysis, MS, NMR and X-ray diffraction.

Synthesis of lapachol semicarbazone - A solution of $30 \mathrm{~mL}$ of $0.1 \mathrm{M} \mathrm{NaOH}$ was added to a suspension of 1 $\mathrm{mmol}$ lapachol, yielding a dark red solution. An aqueousmethanolic $(50 \%)$ solution of semicarbazide $(2.5 \mathrm{mmol})$ was added dropwise to the above solution with constant stirring. The mixture was stirred for approximately $23 \mathrm{~h}$, after which time the solution was neutralised with $10 \%$ $\mathrm{HCl}$. The crude product was filtered and washed with cold water. The resulting solid was purified by column chromatography (silica gel 70-230 mesh) using dichloromethane and ethyl acetate as eluents in mixtures with increasing polarity to give the semicarbazone, which was isolated as a yellow solid in a 13\% yield (Chikate et al. 2005). The lapachol semicarbazone was analysed by MS and NMR.

Antimicrobial assays - Microorganism targets - The antimicrobial activity was evaluated using the following microorganisms from the American Type Culture Collection (ATCC) (Rockville, MD, USA): S. aureus ATCC 25295, Escherichia coli ATCC 18804, Salmonella typhimurium ATCC 14028, Pseudomonas aeruginosa ATCC 49189, Enterococcus faecalis ATCC 19433, Candida albicans ATCC 18804, Candida parapsilosis ATCC 22019, Candida tropicalis ATCC 750 and Cryptococcus gattii ATCC 32608. In addition, 11 clinical Paracoccidioides brasiliensis strains were obtained: $\mathrm{Pb}-01$ ATCCMYA-826, Pb-18 [Fungi Collection of the Faculty of Medicine of the São Paulo University, São Paulo, state of São Paulo (SP), Brazil], Pb-B339 ATCC 32069, Pb-14 (clinical isolate from an acute PCM patient, $\mathrm{SP}$ ), $\mathrm{Pb}-3$, 
$\mathrm{Pb}-4$ (clinic isolates from chronic $\mathrm{PCM}$ patients, $\mathrm{SP}$ MHH Forjaz/TIE Svidzinski), Pb-2 (Epm 60), Pb-1578, $\mathrm{Pb}-8, \mathrm{~Pb}-\mathrm{ED} 01$ and $\mathrm{Pb}-11$ (clinic isolates from acute PCM patients, state of Paraná, Brazil, TIE Svidzinski). The bacterial strains were maintained on brain heart infusion agar (Difco, USA). All the fungal strains were maintained on Sabouraud dextrose agar (Oxoid, Basingstoke, UK). The $P$. brasiliensis strains were maintained in yeast-peptone-dextrose (YPD).

Culture media and inocula - Mueller-Hinton broth (HiMedia, India) was prepared in accordance with the Clinical and Laboratory Standards Institute (CLSI) document M7-A6 (NCCLS 2003) for minimal inhibitory concentration (MIC) bacterial assays. Inocula of all the bacteria were prepared using the spectrophotometric method according to CLSI M7-A6 (NCCLS 2003) at a final concentration of $5 \times 10^{5}$ colony-forming unit $/ \mathrm{mL}$. The fungal cultures of the Candida species and $C$. gattii were freshly grown at $35^{\circ} \mathrm{C}$ and the inoculum suspensions were prepared by the spectrophotometric method according to the CLSI document M27-A3 (CLSI 2008) with a final concentration of $1.5 \pm 1.0 \times 10^{3}$ cells $/ \mathrm{mL}$ for susceptibility tests. A weekly passage on solid YPD medium at $37^{\circ} \mathrm{C}$ was performed to grow $P$. brasiliensis. Yeast cells in the exponential phase were collected aseptically with a sterile loop and resuspended in a tube containing $5 \mathrm{~mL}$ of sterile saline. Large aggregates were allowed to settle for several minutes and the supernatants were collected. The suspensions were diluted in synthetic RPMI medium (Sigma-Aldrich, St. Louis, MO, USA) containing L-glutamine and buffered to $\mathrm{pH} 7.0$ with $0.165 \mathrm{M}$ morpholine propanesulfonic acid (Sigma-Aldrich). The suspensions were prepared according to the CLSI document M27-A3 to obtain a final inoculum size suitable for each strain (CLSI 2008). After homogenisation of the inocula by vortexing, the transmittance was measured at $520 \mathrm{~nm}$ and adjusted to $69-70 \%$ (Hahn \& Hamdan 2000).

Susceptibility test - Broth microdilution testing was performed in accordance with the guidelines presented in the CLSI documents M7-A6 (NCCLS 2003) for bacteria and M27-A3 for fungi (CLSI 2008). The susceptibility to antimicrobial agents was determined by the microbroth dilution method and was performed in sterile flat-bottom 96-well microplates (Difco, Detroit, MI, USA).

The compounds were dissolved in dimethyl sulfoxide (DMSO) after the addition of Mueller-Hinton broth for the bacterial assays or RPMI for the fungal assays. Subsequently, serial dilutions were prepared using the corresponding media as the diluent, maintaining a constant volume of $1 \mathrm{~mL}$ in each tube. The compounds were tested at eight concentrations from 0.006-0.84 $\mu \mathrm{mol} /$ $\mathrm{mL}$. For each dilution, aliquots of $0.1 \mathrm{~mL}$ were added to the wells of the microplates.

For a growth and sterility control, media was used without the addition of extract or solvent. As a control for the toxicity of the solvent, a culture was inoculated with DMSO. Chloramphenicol (2.41 x $10^{-3}$ to $0.31 \mu \mathrm{mol} /$ $\mathrm{mL}$; Sigma-Aldrich) was used as a positive antibacterial control. Amphotericin B $\left(3.25 \times 10^{-5}\right.$ to $0.03 \mu \mathrm{mol} / \mathrm{mL}$;
Sigma-Aldrich) and trimethoprim/sulphamethoxazole ( $4.49 \times 10^{-3}$ to $2.3 \mu \mathrm{mol} / \mathrm{mL}$; Roche, state of Rio de Janeiro, Brazil) were utilised as positive antifungal controls.

After the plates were prepared, the inocula of each bacterial and fungal strain were added and the plates were incubated at $37^{\circ} \mathrm{C}$ for $24 \mathrm{~h}$ for the bacteria, $48 \mathrm{~h}$ for $\mathrm{Can}$ dida spp, $72 \mathrm{~h}$ for $C$. gattii and 10 days for P. brasiliensis. Each test was performed in triplicate. The endpoints were determined visually by comparison of the samples with the drug-free control well. The MIC was defined as the lowest compound concentration at which the well was optically clear and was expressed in $\mu \mathrm{mol} / \mathrm{mL}$.

Sorbitol protection assays - The MICs were determined using P. brasiliensis strain $\mathrm{Pb} 18$ by the standard broth microdilution procedure described above. Duplicate plates were prepared: one contained lapachol thiosemicarbazone and $0.8 \mathrm{M}$ sorbitol as an osmotic support and the other contained lapachol thiosemicarbazone alone. The MICs were determined after 10 days (Escalante et al. 2008).

Human PBMCs - PBMCs were prepared using a modified version of the protocol previously described by Gazzinelli et al. (1983). Briefly, PBMC samples were obtained via an agreement with the Minas Gerais Haematology and Haemotherapy Centre Foundation (protocol 105/2004). The PBMCs were obtained from healthy adult volunteers of both sexes by the centrifugation of heparinised venous blood over a Ficoll cushion (SigmaAldrich, St. Louis, MO). The mononuclear cells were collected from the interphase after Ficoll separation and were washed three times in RPMI-1640 medium before further processing. All the cultures were grown in RPMI-1640 medium (Sigma-Aldrich) supplemented with $5 \%(\mathrm{v} / \mathrm{v})$ heat-inactivated, pooled $\mathrm{AB}(\mathrm{GIBCO} /$ BRL, Grand Island, NY) sera and $2 \mathrm{mM}$ L-glutamine. An antibiotic/antimycotic solution containing 1,000 U/ $\mathrm{mL}$ penicillin, $1000 \mu \mathrm{g} / \mathrm{mL}$ streptomycin and $25 \mu \mathrm{g} / \mathrm{mL}$ fungizone (GIBCO/BRL, Grand Island, NY) was added to prevent fungal and bacterial contamination.

Analysis of cell viability - The PBMCs were cultured in 96-well plates at a density of 200,000 cells/well in a final volume of $0.2 \mathrm{~mL} / \mathrm{well}$. The plates were preincubated in a humidified 5\% $\mathrm{CO}_{2} / 95 \%$ air atmosphere at $37^{\circ} \mathrm{C}$ for $24 \mathrm{~h}$ to allow the cells to adapt prior to the addition of the test compounds. All the compounds were dissolved in DMSO prior to dilution. The toxicity was determined over a concentration range of 0.3-200 $\mu \mathrm{g} /$ $\mathrm{mL}$. All the cell cultures were incubated in a humidified $5 \% \mathrm{CO}_{2} / 95 \%$ air atmosphere at $37^{\circ} \mathrm{C}$ for $48 \mathrm{~h}$. The cell viability was estimated by measuring the rate of the mitochondrial reduction of a yellow tetrazolium salt, 2-(3,5-diphenyltetrazol-2-ium-2-yl)-4,5-dimethyl-1,3-thiazole bromide (MTT) (Sigma-Aldrich, St. Louis, $\mathrm{MO}$, to insoluble purple formazan crystals (Mosmann 1983). After incubation of the cultures with the test compounds, the MTT solution $(0.020 \mathrm{~mL}$ at $5 \mathrm{mg} / \mathrm{mL})$ was added to each well and the plates were incubated for 4 $\mathrm{h}$. At the end of this incubation, the supernatant was removed and $0.04 \mathrm{M} \mathrm{HCl}$ in isopropyl alcohol $(200 \mu \mathrm{L})$ 
was added to dissolve the formazan crystals. The optical densities were measured with a spectrophotometer at a wavelength of $590 \mathrm{~nm}$. The results were normalised to the DMSO control $(0.01 \%)$ and were expressed as the per cent inhibition of cell viability. The interactions between the compounds and the media were estimated based on the variations between the drug-containing medium and the drug-free medium to control for false-positive and false-negative results. The data were analysed using Prism 5.0 (GraphPad Software, Inc).

Statistical analyses - All the PBMC results were expressed as the mean \pm standard deviation of three independent experiments that were performed at least in triplicate. These data were analysed using Student's $t$ test for paired comparisons. A p value of less than 0.05 indicated statistical significance.

\section{RESULTS}

The reactions of lapachol (compound 1) with thiosemicarbazide and semicarbazide gave a thiosemicarbazone (compound 2) and a semicarbazone (compound 3) with yields of $73 \%$ and $13 \%$, respectively (Fig. 1). The ESI-MS data for compound 2 showed a positive ion peak at $\mathrm{m} / \mathrm{z} 316$, which was attributed to the quasi-molecular ion peak $[\mathrm{M}+\mathrm{H}]^{+}$and the ESI-MS of compound 3 exhibited a negative ion peak at $\mathrm{m} / \mathrm{z} 298$, which was attributed to the quasi-molecular ion peak $[\mathrm{M}-\mathrm{H}]$; ; these quasimolecular ion peaks correspond with the expected molecular weights of 315 and $299 \mathrm{~g} / \mathrm{mol}$ for the compound 2 and the compound 3 , respectively. The compound 2 had a melting point of $174.3-175.3^{\circ} \mathrm{C}$.

The comparison of the ${ }^{1} \mathrm{H}$ spectra (Table I) between lapachol and its derivatives (compounds 2 and 3 ) indicat-<smiles>CC(C)=CCC1=C(O)C(=O)c2ccccc2C1=O</smiles>

Lapachol

B<smiles>CC(C)=CCC1=C(O)C(=O)c2ccccc2C1=O</smiles>

Lapachol

C<smiles>CC(C)=CCC1=C(O)C(=O)c2ccccc2C1=O</smiles>

$+\quad \mathrm{H}_{2} \mathrm{NC}(=\mathrm{S}) \mathrm{NHNH}_{2} \longrightarrow$

Thiosemicarbazide<smiles>CC(C)=CCC1=C(O)c2ccccc2C(=NN(C)C(=S)N(C)c2ccccc2)C1=O</smiles><smiles>CC(C)=CCC1=C(O)c2ccccc2C(=NN(C)C(=S)N(P)c2ccccc2)C1=O</smiles><smiles>CC(C)=CCC1=C(O)c2ccccc2C(=NN(C)C(=O)N(P)c2ccccc2)C1=O</smiles>

Semicarbazone<smiles>CC(C)=CCC1=C(C)c2ccccc2C(=NN(C)C(=O)N(P)c2ccccc2)C1=O</smiles>

Fig. 1: synthesis of lapachol thiosemicarbazone and semicarbazone and structures of lapachol (A), lapachol derivatives thiosemicarbazone (B) and semicarbazone (C). 
TABLE I

${ }^{1} \mathrm{H}$ nuclear magnetic resonance (NMR) [400 MHz, dimethyl sulfoxide (DMSO), $\left.\delta, J(\mathrm{~Hz})\right]$ and ${ }^{13} \mathrm{C}$ NMR (100 MHz, DMSO, $\delta$ ) data for lapachol, thiosemicarbazone and semicarbazone

\begin{tabular}{|c|c|c|c|c|c|c|}
\hline & \multicolumn{3}{|c|}{${ }^{1} \mathrm{H}$ NMR } & \multicolumn{3}{|c|}{${ }^{13} \mathrm{C}$ NMR } \\
\hline & Lapachol & Thiosemicarbazone & Semicarbazone & Lapachol & Thiosemicarbazone & Semicarbazone \\
\hline 1 & - & - & - & 181.00 & 129.53 & 129.21 \\
\hline 2 & - & - & - & 154.98 & 180.44 & 181.00 \\
\hline 3 & - & - & - & 122.87 & 117.39 & 117.23 \\
\hline 4 & - & - & - & 184.10 & 163.62 & 163.00 \\
\hline 5 & $7.95 \mathrm{~m}$ & $8.00 \mathrm{~d}(7.2)$ & $7.98 \mathrm{~d}(6.4)$ & 125.52 & 123.25 & 123.55 \\
\hline 6 & 7.76 t (7.2) & $7.55 \mathrm{~m}$ & $7.50 \mathrm{~m}$ & 134.37 & 128.82 & 128.09 \\
\hline 7 & $7.81 \mathrm{t}(7.0)$ & $7.57 \mathrm{~m}$ & $7.53 \mathrm{~m}$ & 133.16 & 129.93 & 129.74 \\
\hline 8 & $7.97 \mathrm{~m}$ & $8.64 \mathrm{~d}(7.2)$ & $8.50 \mathrm{~d}(6.4)$ & 125.60 & 123.78 & 123.49 \\
\hline 9 & - & - & - & 129.85 & 131.28 & 131.61 \\
\hline 10 & - & - & - & 131.83 & 127.08 & 126.41 \\
\hline 11 & $3.15 \mathrm{~d}(7.2)$ & $3.27 \mathrm{~d}(6.8)$ & $3.26 \mathrm{~d}(6.6)$ & 21.95 & 21.15 & 21.16 \\
\hline 12 & $5.11 \mathrm{t}(7.2)$ & $5.10 \mathrm{t}(6.8)$ & 5.09 t (6.6) & 120.60 & 122.00 & 122.16 \\
\hline 13 & - & - & - & 131.86 & 131.14 & 131.03 \\
\hline 14 & $1.71 \mathrm{~s}$ & $1.65 \mathrm{~s}$ & $1.75 \mathrm{~s}$ & 17.66 & 17.88 & 17.88 \\
\hline 15 & $1.62 \mathrm{~s}$ & $1.53 \mathrm{~s}$ & $1.63 \mathrm{~s}$ & 25.35 & 25.45 & 25.47 \\
\hline 16 & - & - & - & - & 179.51 & 155.45 \\
\hline $2(\mathrm{NH})$ & - & $14.94 \mathrm{~s}$ & $14.26 \mathrm{~s}$ & - & - & - \\
\hline $3\left(\mathrm{NH}_{\mathrm{a}}\right)$ & - & $9.22 \mathrm{~s}$ & $7.32 \mathrm{~b}$ & - & - & - \\
\hline $3\left(\mathrm{NH}_{\mathrm{b}}\right)$ & - & $8.96 \mathrm{~s}$ & $7.32 \mathrm{~b}$ & - & - & - \\
\hline
\end{tabular}

ed that the signals from the side-chain at C-3 were virtually unchanged. In addition, the N2-H chemical shifts at 14.94 and 14.26 in the spectra of 2 and 3 were indicative of conformations in which $\mathrm{N} 2-\mathrm{H}$ is hydrogen bonded to $\mathrm{O}-2$. The N3-Ha and N3-Hb hydrogens of 2 were diastereotopic. The different chemical shifts likely result from a hydrogen bond between N3-Ha and N1, indicating that the same conformation that has been suggested in solution is found in the solid state.

Changes were predominantly observed in the ${ }^{13} \mathrm{C}$ NMR spectrum (Table I). Shielding effects were observed at C-1 $\left[\delta_{C} 129.53(2)\right.$ and $\left.129.21(3)\right]$, C-4 $\left[\delta_{C} 163.62\right.$ (2) and $163.00(3)]$ and C-3 [ $\delta_{C} 117.39$ (2) and 117.23 (3)] with the carbonyl group of lapachol being replaced with an imine group (C-1), a hydroxyl group (C-4) or a C3-C4 double bond in the obtained products. Changes in the values of the aromatic ring and a deshielding effect at C-2 $\left[\delta_{C} 180.44\right.$ (2) and 181.00 (3)] compared with lapachol $\left(\delta_{C} 154.98\right)$ suggested the formation of a carbonyl group at $\mathrm{C}-2$. The ${ }^{13} \mathrm{C}$ signals related to the thiosemicarbazone (compound 2) and semicarbazone (compound 3 ) moieties were observed at $\delta_{\mathrm{C}} 179.51(\mathrm{C}=\mathrm{S})$ for 2 and at $\delta_{\mathrm{C}} 155.45(\mathrm{C}=\mathrm{O})$ for 3 (Table I). The COSY, HMQC and HMBC spectra were used to confirm the structures and to unambiguously assign the chemical shifts for all the hydrogen and carbon atoms of 2 and 3 (Table I).

The presence of the thiosemicarbazone and semicarbazone moieties at C-1 was confirmed by the observation of $\mathrm{N} 2-\mathrm{H} \cdots \mathrm{O} 1$ hydrogen bonds in (2) and (3) and by the heteronuclear long-range couplings of the hydrogen and carbon atoms that were revealed by the cross-peaks in the HMBC spectra. These cross-peaks corresponded to the spin-spin interactions of $\mathrm{H}-11\left[\delta_{\mathrm{H}} 3.27\right.$ (2) and 3.26 (3)] with C-2 $\left[\delta_{\mathrm{C}} 181.00(3)\right]$ and C-4 $\left[\delta_{\mathrm{C}} 163.62(2)\right.$ and $163.00(3)]$ and of H-5 with C-4 $\left[\delta_{C} 163.62\right.$ (2)].

Fig. 2 presents a perspective view of the lapachol thiosemicarbazone. The crystal data and refinement results are listed in Table II. Selected intramolecular bond distances and angles in the structure are presented in Table III. The bond lengths and angles for the lapachol moiety are in good agreement with the values that were reported for Hooker's "lapachol peroxide" (Júnior et al. 2009). The most significant differences are the $\mathrm{C}-\mathrm{O}$ bonds. The $\mathrm{C}-\mathrm{O}$ distance varies from 1.364-1.431 $\AA$ for the single bonds and from 1.209-1.227 $\AA$ for the double bonds in Hooker's lapachol structure. In lapachol thiosemicarbazone, the C4-O2 (1.350(2) A) single bond is shorter and the C2-O1 $[1.236(2) \AA]$ double bond is longer. The bond distances and angles in the thiosemicarbazone framework are similar to the bonds and angles in other thiosemicarbazones (Beraldo et al. 2001, Lessa et al. 2010).

Lapachol thiosemicarbazone adopts the $E$ conformation with respect to the $\mathrm{N} 2-\mathrm{C} 16$ bond in the solid state. A weak intramolecular $\mathrm{N} 2-\mathrm{H} \cdots \mathrm{O} 1$ hydrogen bond (Table IV) is present in the structure, but is not likely to facilitate rotation around the $\mathrm{N} 2-\mathrm{C} 16$ bond. The same conformation occurs in 2 in a DMSO solution, as was discussed earlier. In the compound packing, weak intermolecular $\mathrm{O} 2-\mathrm{H} \cdots \mathrm{S} 1$ and $\mathrm{N} 3-\mathrm{H} \cdots \mathrm{O} 2$ hydrogen bonds result in the formation of linear arrangements in the solid state (Fig. 3). 


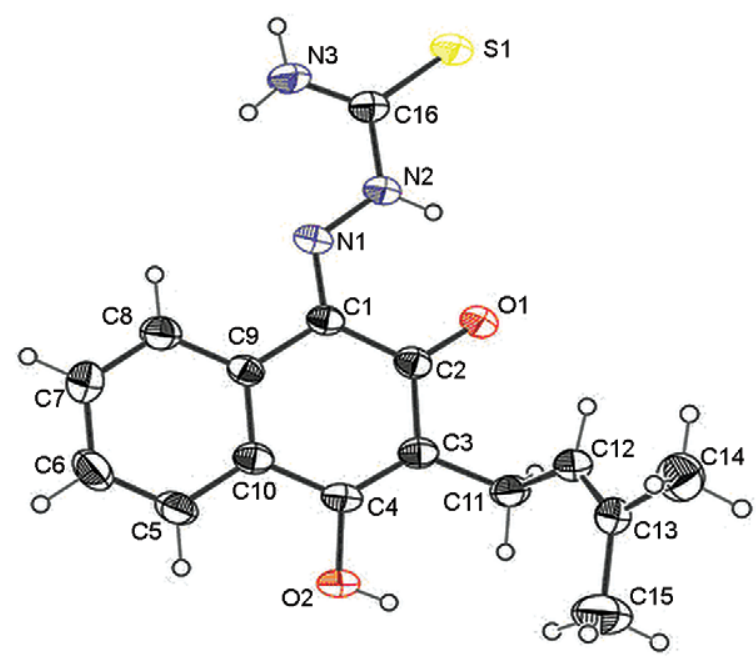

Fig. 2: molecular plot of lapachol thiosemicarbazone showing the labelling scheme of the non-H atoms and their displacement ellipsoids at the $50 \%$ probability level.

The lapachol thiosemicarbazone and semicarbazone derivatives were tested against five pathogenic bacteria (E. coli, S. aureus, P. aeruginosa, S. typhimurium and E. faecalis). The most effective antimicrobial activities were observed against two pathogenic Gram-positive bacteria, S. aureus and E. faecalis (Table V). These compounds were inactive against Gram-negative bacteria. The lapachol thiosemicarbazone and semicarbazone derivatives had MICs of $0.10 \mu \mathrm{mol} / \mathrm{mL}$ against $S$. aureus and $0.05 \mu \mathrm{mol} / \mathrm{mL}$ against E. faecalis. Lapachol inhibited the growth of $S$. aureus and E. faecalis at a concentration of $0.52 \mu \mathrm{mol} / \mathrm{mL}$. The semicarbazide and thiosemicarbazide reagents were tested against five pathogenic bacteria and were active against $E$. faecalis, inhibiting its growth at a concentration of 0.83 and $0.69 \mu \mathrm{mol} / \mathrm{mL}$, respectively (Table $\mathrm{V}$ ).

Lapachol was tested against opportunistic Candida sp., C. gattii and P. brasiliensis. It had superior activity only against $P$. brasiliensis; the MIC was $0.13 \mu \mathrm{mol} /$ $\mathrm{mL}$ for most of the isolates and $0.26 \mu \mathrm{mol} / \mathrm{mL}$ for $P$. brasiliensis 01 .

The lapachol thiosemicarbazone derivative exhibited the best antifungal activity, with MICs ranging from $0.01-0.10 \mu \mathrm{mol} / \mathrm{mL}$ for the isolates of $P$. brasiliensis. The lapachol semicarbazone derivative was less active than the thiosemicarbazone derivative against the $P$. brasiliensis isolates (MICs 0.42 vs. $0.84 \mu \mathrm{mol} / \mathrm{mL}$, respectively). $C$. albicans and $C$. tropicalis were resistant to the thiosemicarbazone and semicarbazone derivatives at the tested concentrations. $C$. gattii was susceptible to the thiosemicarbazone and semicarbazone derivatives, with MICs of 0.10 and $0.21 \mu \mathrm{mol} / \mathrm{mL}$, respectively. The semicarbazide and thiosemicarbazide reagents were inactive against all fungi tested except $P$. brasiliensis isolates, the growth of which was inhibited by the thiosemicarbazide reagent at a concentration of $1.37 \mu \mathrm{mol} / \mathrm{mL}$.

In this study, the lapachol thiosemicarbazone derivative had the greatest activity against $P$. brasiliensis;
TABLE II

Crystal data and refinement results for lapachol thiosemicarbazone

\begin{tabular}{|c|c|}
\hline Empirical formula & $\mathrm{C}_{16} \mathrm{H}_{17} \mathrm{~N}_{3} \mathrm{O}_{2} \mathrm{~S}$ \\
\hline Formula weight & 315.39 \\
\hline Crystal system & Triclinic \\
\hline Space group & P-1 \\
\hline Wavelength, $\AA$ & 0.71073 \\
\hline \multicolumn{2}{|l|}{ Unit cell dimensions } \\
\hline $\mathrm{a}, \AA$ & $6.9260(6)$ \\
\hline $\mathrm{b}, \AA$ & $10.2676(18)$ \\
\hline $\mathrm{c}, \AA$ & $11.0379(8)$ \\
\hline$\alpha, 0$ & $84.659(10)$ \\
\hline$\beta, 0$ & $73.210(7)$ \\
\hline$\gamma, 0$ & $85.264(12)$ \\
\hline Volume, $\AA^{3}$ & $746.94(16)$ \\
\hline $\mathrm{Z}$, density calc, $\mathrm{mg} / \mathrm{m}^{3}$ & $2,1.402$ \\
\hline Absorption coefficient, $\mathrm{mm}^{-1}$ & 0.228 \\
\hline $\mathrm{F}(000)$ & 332 \\
\hline Cristal size, $\mathrm{mm}$ & $0.31 \times 0.28 \times 0.20$ \\
\hline$\theta$ range for data coll., ${ }^{\circ}$ & $2.88-26.37$ \\
\hline \multirow[t]{3}{*}{ Index range, $\theta$} & $-8<=h<=8$ \\
\hline & $-12<=\mathrm{k}<=12$ \\
\hline & $-13<=1<=13$ \\
\hline \multirow[t]{2}{*}{ Completeness } & $\theta=26.37^{\circ}$ \\
\hline & $99.9 \%$ \\
\hline Goodness-of-fit on $F^{2}$ & 0.960 \\
\hline Reflec. collect./unique & $8729 / 3049$ \\
\hline Data/restraints/parameters & $8729 / 0 / 202$ \\
\hline Observed reflections, $\mathrm{I}>2 \sigma(\mathrm{I})$ & 5780 \\
\hline Final $R$ indices $[\mathrm{I}>2 \sigma(\mathrm{I})]$ & $\begin{array}{c}R_{1}=0.0466 \\
w R_{2}=0.1127\end{array}$ \\
\hline$R$ indices (all data) & $\begin{array}{l}R_{1}=0.0800 \\
w R_{2}=0.1289\end{array}$ \\
\hline Larg. peak and hole, e $\AA^{-3}$ & $0.265 /-0.255$ \\
\hline
\end{tabular}

therefore, its effect on the fungal cell wall was determined using the sorbitol assay. A distinctive feature of specific inhibitors of fungal cell wall synthesis is that the antifungal effect is reversed in media containing an osmotic stabiliser such as sorbitol (Frost et al. 1995). However, the lapachol thiosemicarbazone derivative did not affect the fungal cell wall because the MIC for $P$. brasiliensis did not change upon the addition of sorbitol to the culture medium.

Compared with the control $(0.01 \%$ DMSO), the lapachol-derived thiosemicarbazone did not reduce cell viability over the concentration range of $9.52 \times 10^{-4}$ to 0.32 $\mu \mathrm{mol} / \mathrm{mL}(0.3-100 \mu \mathrm{g} / \mathrm{mL})$, but at $0.64 \mu \mathrm{mol} / \mathrm{mL}(200 \mu \mathrm{g} /$ $\mathrm{mL})$, this compound significantly reduced cell viability, indicating cytotoxicity (Fig. 4). The MICs for this compound against the isolates of $P$. brasiliensis were in the range of $0.10-5.40 \times 10^{-3} \mu \mathrm{mol} / \mathrm{mL}(31.2-1.7 \mu \mathrm{g} / \mathrm{mL})$. For 
E. faecalis and S. aureus, the MICs were between 0.10$0.05 \mu \mathrm{mol} / \mathrm{mL}$ (between $31.2-15.6 \mu \mathrm{g} / \mathrm{mL}$ ). These results indicate that the lapachol-derived thiosemicarbazone is not cytotoxic against normal cells at the concentrations that were active against fungi and bacteria. Conversely, lapachol had a biphasic dose-response curve, exhibiting toxicity at both the maximal concentration of $0.83 \mu \mathrm{mol} /$ $\mathrm{mL}(200 \mu \mathrm{g} / \mathrm{mL})$ and the intermediate concentration of $0.01 \mu \mathrm{mol} / \mathrm{mL}(3 \mu \mathrm{g} / \mathrm{mL})$. At $0.01 \mathrm{mmol} / \mathrm{mL}(3 \mathrm{mg} / \mathrm{mL})$, there was a significant reduction in cell viability compared with the control $(0.01 \%$ DMSO). At the other tested concentrations, this compound was not toxic. The MICs for lapachol against $P$. brasiliensis and the two tested bacterial strains were in the range of $0.52-0.13 \mu \mathrm{mol} / \mathrm{mL}$ $(124-31.2 \mu \mathrm{g} / \mathrm{mL})$ and $0.52-0.06 \mu \mathrm{mol} / \mathrm{mL}(125-15.6 \mu \mathrm{g} /$ $\mathrm{mL}$ ), respectively, and no toxicity was observed against the PBMCs at these concentrations.

Supplementary material - CCDC reference 844492 for 2 contains the supplementary crystallographic data. These data can be obtained free of charge from the CCDC via ccdc.cam.ac.uk/data_request/cif.

\section{DISCUSSION}

In this study, we determined the MICs for lapachol and its derivatives against clinical pathogens and the results indicate that these compounds were active against C. gattii, several isolates of P. brasiliensis and Grampositive bacteria, including $S$. aureus and $E$. faecalis.

TABLE III

Selected bond distances $(\AA)$ for lapachol thiosemicarbazone

\begin{tabular}{lccc}
\hline Atoms & $\begin{array}{c}\text { Bond distance } \\
(\AA)\end{array}$ & Atoms & $\begin{array}{c}\text { Angle } \\
\left({ }^{\circ}\right)\end{array}$ \\
\hline C1-N1 & $1.307(2)$ & C1N1N2 & $119.36(15)$ \\
N1-N2 & $1.342(2)$ & N1N2C16 & $119.01(15)$ \\
N2-C16 & $1.365(2)$ & N2C16N3 & $115.96(15)$ \\
C16-N3 & $1.312(2)$ & N2C16S1 & $118.81(13)$ \\
C16-S1 & $1.668(2)$ & N3C16S1 & $125.23(14)$ \\
C2-O1 & $1.236(2)$ & $\mathrm{C} 1 \mathrm{C} 2 \mathrm{O} 1$ & $120.47(15)$ \\
C4-O2 & $1.350(2)$ & C3C2O1 & $120.79(16)$ \\
C3-C11 & $1.510(2)$ & C10C4O2 & $112.30(15)$ \\
C12-C13 & $1.317(2)$ & C3C4O2 & $123.81(17)$ \\
\hline
\end{tabular}

The lapachol semicarbazone derivative had weaker antimicrobial activity than the lapachol thiosemicarbazone. Although semicarbazones have extensive pharmacological profiles, many activities are lost or diminished by the substitution of the sulphur for oxygen (Beraldo 2004).

The activity against $E$. faecalis is promising because this bacterium has adapted such that it can survive and prevail in the bacterial flora that colonise the gastrointestinal tract of critically ill, immunocompromised and/ or neutropenic patients. Consequently, the number of severe enterococci infections is increasing, especially in tertiary hospitals (McBride et al. 2007). The thiosemicarbazone and semicarbazone derivatives of lapachol

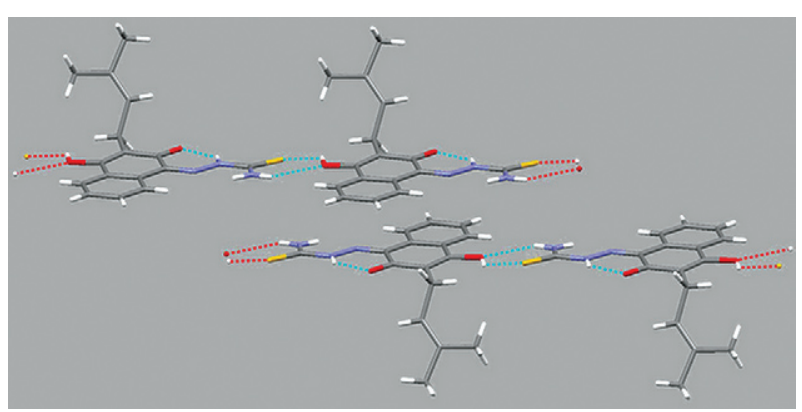

Fig. 3: molecular packing of lapachol thiosemicarbazone showing the scheme of hidrogen bonding.
Viability (\%)

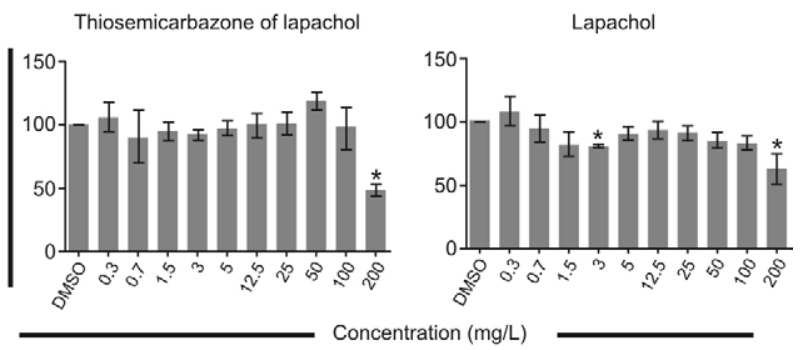

Fig. 4: impact of thiosemicarbazone of lapachol and lapachol on viability of human peripheral blood mononuclear cells. The cells were incubated with different concentrations of compounds for $48 \mathrm{~h}$ and viability was determinated by 2-(3,5-diphenyltetrazol-2-ium-2-yl)-4,5-dimethyl-1,3-thiazole bromide assay. The values represent means \pm standard deviation from six independent experiments (asterisk means $\mathrm{p}<0.05$, Student $t$ test). DMSO: dimethyl sulfoxide.

TABLE IV

Hydrogen bonds distances $(\AA)$ and angles $\left(^{\circ}\right)$ for lapachol thiosemicarbazone with d $(\mathrm{H} . . \mathrm{A})<\mathrm{r}(\AA)+2.00 \AA$ and $<\mathrm{D}-\mathrm{H} \cdots \mathrm{A}>110^{\circ}$

\begin{tabular}{lccccc}
\hline $\mathrm{D}-\mathrm{H} \cdots \mathrm{A}$ & $\mathrm{d}(\mathrm{D}-\mathrm{H})$ & $\mathrm{d}(\mathrm{H} \cdots \mathrm{A})$ & $\mathrm{d}(\mathrm{D} \cdots \mathrm{A})$ & $(\mathrm{D}-\mathrm{H} \cdots \mathrm{A})$ & Symmetry operation \\
\hline $\mathrm{N} 3-\mathrm{H} 3 \mathrm{~B} \cdots \mathrm{O} 2$ & 0.86 & 2.32 & $3.0805(18)$ & 147.4 & {$[\mathrm{x}, \mathrm{y}, \mathrm{z}-1]$} \\
$\mathrm{O} 2-\mathrm{H} 2 \cdots \mathrm{S} 1$ & 0.82 & 2.49 & $3.1556(14)$ & 139.3 & {$[\mathrm{x}, \mathrm{y}, \mathrm{z}+1]$} \\
$\mathrm{N} 2-\mathrm{H} 2 \mathrm{~A} \cdots \mathrm{O} 1$ & 0.86 & 1.90 & $2.5682(18)$ & 133.2 & intramolecular \\
\hline
\end{tabular}




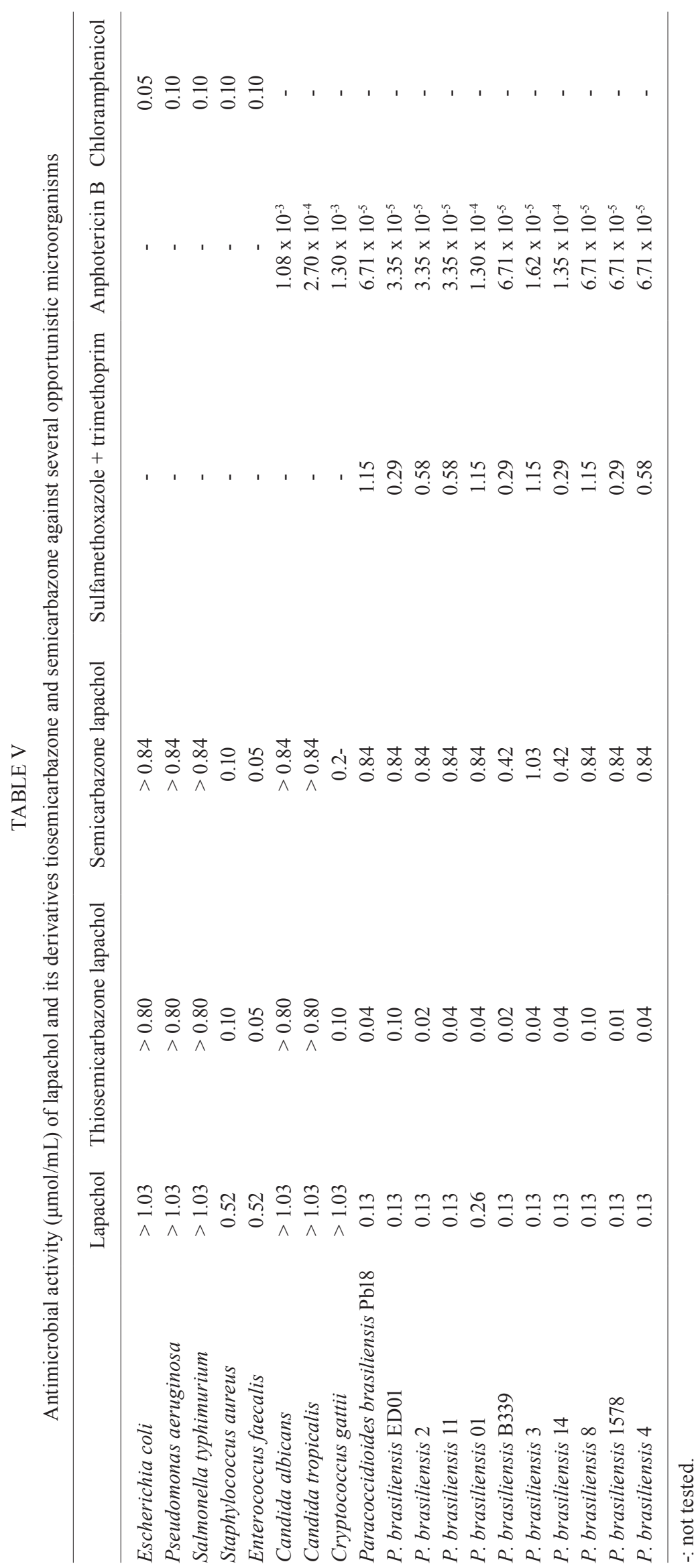


were two-fold more active than chloramphenicol against E. faecalis and had MICs similar to that of chloramphenicol when tested against $S$. aureus. $S$. aureus causes staphylococcal infections and following the introduction of methicillin, there has been a steady increase in methicillin-resistant $S$. aureus isolates that are resistant to vancomycin, even in Brazil (Palazzo et al. 2005).

The initial studies, conducted at the Department of Antibiotics at the Federal University of Pernambuco in 1973, demonstrated the robust activity of lapachol against Gram-positive bacteria (Lima \& Weigert 1972, Nagata et al. 1998). These studies revealed that lapachol was active against Helicobacter pylori, Staphylococcus, Streptococcus, Enterococcus, Bacillus and Clostridium, with MICs ranging from 1,560-25,000 $\mu \mathrm{g} / \mathrm{mL}$ (Almeida 2009). In general, thiosemicarbazones obtained from other sources, in particular, $\alpha-(\mathrm{N})$-heterocyclic thiosemicarbazones and their metal complexes, inhibit the growth of Gram-positive bacteria, such as Neisseria gonorrhoeae, Neisseria meningitides, Staphylococcus faecalis, Streptococcus faecalis and Enterococcus, but do not effectively inhibit Gram-negative bacteria, such as Pseudomonas, Klebsiella, Enterobacter, Shigella, E. coli and Proteus (Beraldo 2004).

In this study, the lapachol-derived thiosemicarbazone had superior antimicrobial activity against clinical isolates of $P$. brasiliensis. Our data indicated that the lapachol thiosemicarbazone derivative was more active than sulphonamides, the first class of drugs available for treating patients with PCM. This finding is important because the use of sulphonamides for more than two years may be required to treat PCM. Moreover, there is increasing concern about drug toxicity and treatment cost (Brummer et al. 1993, Paniago et al. 2003, Travassos et al. 2008).

The lapachol-derived semicarbazone and thiosemicarbazone also exhibited antimicrobial activity against C. gattii (Table V). These results are significant because this pathogenic yeast primarily infects healthy individuals and has a high mortality rate (Chaturvedi et al. 2005). Amphotericin B, alone or in combination with flucytosine, remains the standard antifungal therapy for these infections, despite the toxicity of both drugs (Lima \& Weigert 1972). Other drugs, such as fluconazole and itraconazole, are used as oral maintenance or consolidation therapy for cryptococcosis (Perfect \& Casadevall 2002). However, resistance to fluconazole has arisen in recent years (Sabbatani et al. 2004).

Lapachol was previously tested against $C$. albicans and Cladosporium cucumerinum on silica gel plates and it exhibited antimicrobial activity at minimal concentrations of 0.04 and $2.48 \times 10^{-3} \mu \mathrm{mol} / \mathrm{mL}$, respectively (Gafner et al. 1996). However, the MICs for lapachol were not determined. In addition, it has been reported that analogues of furanonaphthoquinone from Tecoma ipe have MICs of $1-8 \mu \mathrm{g} / \mathrm{mL}$ against several pathogenic fungi (Nagata et al. 1998), indicating a therapeutic potential for naphthoquinones against fungi.

Lapachol and its thiosemicarbazone derivative had dramatic antifungal activity. Lapachol is known for its antimicrobial activity, but its thiosemicarbazone de- rivative has never been described. In this study, this derivative was found to be superior to lapachol in terms of antifungal activity.

Our data demonstrate that these derivatives were less toxic than lapachol, which exhibited a biphasic response with toxicity at higher concentrations and hormesis at $0.01 \mu \mathrm{mol} / \mathrm{mL}(3 \mu \mathrm{g} / \mathrm{mL})$. Hormesis describes a dose-response curve with opposite effects at low doses vs. high doses (Hoffman 2009). Therefore, the in vitro cytoxicity assays performed using immune system cells revealed a potentially greater immunotoxicity for lapachol than for its derivatives.

The MICs for the lapachol-derived thiosemicarbazone against pathogenic bacteria (S. aureus and E. faecalis) and fungi (mainly P. brasiliensis) indicate that these compounds are excellent choices for the development of novel drugs to treat microbial infections. Further studies are necessary to verify the effectiveness of these compounds in treating infections caused by microorganisms.

\section{REFERENCES}

Almeida ER 2009. Preclinical and clinical studies of lapachol and beta-lapachone. The Open Natural Products Journal 2: 42-47.

Araújo EL, Alencar JRB, Rolim Neto PJ 2002. Lapachol: segurança e eficácia na terapêutica. Rev Bras Farmacogn 12: 57-59.

Beraldo H 2004. Semicarbazonas e tiossemicarbazonas: o amplo perfil farmacológico e usos clínicos. Quim Nova 27: 461-471.

Beraldo H, Lima R, Teixeira LR, Moura AA, West DX 2001. Crystal structures and IR, NMR and UV spectra of 4-formyl and 4-acetylpyridine N(4)-methyl and N(4)-ethylthiosemicarbazones. J Mol Struct 559: 99-106.

Brummer E, Castaneda E, Restrepo A 1993. Paracoccidioidomycosis: an update. Clin Microbiol Rev 6: 89-117.

Chaturvedi S, Dyavaiah M, Larsen RA, Chaturvedi V 2005. Cryptococcus gattii in AIDS patients, southern California. Emerg Infect Dis 11: 1686-1692.

Chikate RC, Belapure AR, Padhye SB, West DX 2005. Transition metal quinone-thiosemicarbazone complexes 1: evaluation of EPR covalency parameters and redox properties of pseudosquare-planar copper (II)-naphthoquinone thiosemicarbazones. Polyhedron 24: 889-899.

CLSI - Clinical and Laboratory Standards Institute 2008. Reference method for broth dilution antifungal susceptibility testing of yeast. Approved Standard M27-A3, CLSI, Wayne, 25 pp.

Coutinho ZF, Silva D, Lazera M, Petri V, Oliveira RM 2002. Paracoccidioidomycosis mortality in Brazil (1980-1995). Cad Saude Publica 18: 1441-1454.

Escalante A, Gattuso M, Pérez P, Zacchino S 2008. Evidence for the mechanism of action of the antifungal phytolaccoside $\mathrm{B}$ isolated from Phytolacca tetrâmera Hauman. J Nat Prod 71: 1720-1725.

Farrugia LJ 1997. ORTEP-3 for Windows - a version of ORTEP-III with a graphical user interface (GUI). J Appl Crystallogr 30: 565.

Farrugia LJ, Win GX 1999. Suite for single crystal small molecule crystallography. J Appl Crystallogr 32: 837.

Fluit AC, Verhoef J, Schmitz FJ 2001. Frequency of isolation and antimicrobial resistance of gram-negative and gram-positive bacteria from patients in intensive care units of 25 European university hospitals participating in the European arm of the SENTRY Antimicrobial Surveillance Program 1997-1998. Eur J Clin Microbiol Infect Dis 20: 617-625. 
Fonseca SGC, Braga RMC, Santana DP 2003. Lapachol: chemistry, pharmacology and assay methods. Rev Bras Farm 84: 9-16.

Frost D, Brandt K, Cugier D 1995. A whole-cell Candida albicans assay for the detection of inhibitors towards fungal cell wall synthesis and assembly. $J$ Antibiot (Tokyo) 48: 306-310.

Gafner S, Wolfender JL, Nianga M, Stoeckli-Evans H, Hostettmann $\mathrm{K}$ 1996. Antifungal and antibacterial naphthoquinones from Newbouldia laevis roots. Phytochemistry 42: 1315-1320.

Gazzinelli G, Katz N, Rocha RS, Colley DG 1983. Immune responses during human schistosomiasis mansoni. X. Production and standardization of an antigen-induced mitogenic activity by peripheral blood mononuclear cells from treated, but not active cases of schistosomiasis. J Immunol 130: 2891-2895.

Hahn RC, Hamdan JS 2000. Effects of amphotericin B and three azole derivatives on the lipids of yeast cells of Paracoccidioides brasiliensis. Antimicrob Agents Chemother 44: 1997-2000.

Hidron AI, Edwards JR, Patel J, Horan TC, Sievert DM, Pollock DA, Fridkin SK, National Healthcare Safety Network Team, Participating National Healthcare Safety Network Facilities 2008. NHSN annual update: antimicrobial-resistant pathogens associated with healthcare-associated infections: annual summary of data reported to the National Healthcare Safety Network at the Centers for Disease Control and Prevention, 2006-2007. Infect Control Hosp Epidemiol 29: 996-1011.

Hoffman GH 2009. A perspective on the scientific, philosophical and policy dimensions of hormesis. Dose Response 7: 1-51.

Johnson CK 1965. ORTEP-I Report ORNL-3794, Oak Ridge National Laboratory, Oak Ridge, Tennessee, USA.

Jones KE, Patel NG, Levy MA, Storeygard A, Balk D, Gittleman JL, Daszak P 2008. Global trends in emerging infectious diseases. Nature 451: 990-993.

Júnior ENS, Pinto MCFR, Moura KCG, Simone CA, Nascimento CJ, Andrade CKZ, Hooker's PAV 2009. Lapachol peroxide' revisited. Tetrahedron Lett 50: 1575-1577.

Lessa JA, Mendes IC, da Silva PR, Soares MA, dos Santos RG, Speziali NL, Romeiro NC, Barreiro EJ, Beraldo H 2010. 2-Acetylpyridine thiosemicarbazones: cytotoxic activity in nanomolar doses against malignant gliomas. Eur J Med Chem 45: 5671-5677.

Lima OG, Weigert E 1972. Atividade antimicrobiana e antineoplásica de juglona, lapachol e plumbagina. Rev Ints Antibiot 12: 3-12.

McBride SM, Fischetti VA, LeBlanc DJ, Moellering Jr RC, Gilmore MS 2007. Genetic diversity among Enterococcus faecalis. PLoS ONE 2: e582.

Mosmann T 1983. Rapid colorimetric assay for cellular growth and survival: application to proliferation and cytotoxicity assays. J Immunol Methods 65: 55-63.
Nagata K, Hirai KI, Koyama J, Wada Y, Tamura T 1998. Antimicrobial activity of novel furanonaphthoquinone analogs. Atimicrob Agents Chemother 42: 700-702.

NCCLS - National Committee for Clinical Laboratory Standards 2003. Methods for dilution antimicrobial susceptibility tests for bacteria that grow aerobically, NCCLSI document M7-A6, 6th ed., NCCLS, Wayne, 53 pp.

Palazzo ICV, Araujo MLC, Darini ALC 2005. First report of vancomycin-resistant Staphylococci isolated from healthy carriers in Brazil. J Clin Microbiol 43: 179-185.

Paniago AMM, Aguiar JIA, Aguiar ES, Cunha RV, Pereira GROL, Londero AT, Wanke B 2003. Paracoccidioidomicose: estudo clínico e epidemiológico de 422 casos observados no estado de Mato Grosso do Sul. Rev Soc Bras Med Trop 36: 455-459.

Perfect JR, Casadevall A 2002. Cryptococcosis. Infect Dis Clin North Am 16: 837-874.

Rosenthal VD, Maki DG, Jamulitrat S, Medeiros EA, Todi SK, Gomez DY, Leblebicioglu H, Abu Khader I, Miranda Novales MG, Berba R, Ramírez Wong FM, Barkat A, Pino OR, Dueñas L, Mitrev Z, Bijie H, Gurskis V, Kanj SS, Mapp T, Hidalgo RF, Ben Jaballah N, Raka L, Gikas A, Ahmed A, Thu le TA, Guzmán Siritt ME, INICC Members 2010. International nosocomial infection control consortium report, data summary for 2002-2007, issued June 2009. Am J Infect Control 38: 95-104.

Sabbatani S, Manfredi R, Pavoni M, Consales A, Chiodo F 2004. Voriconazole proves effective in long-term treatment of a cerebral cryptococcoma in a chronic nephropathic HIV-negative patient, after fluconazole failure. Mycopathologia 158: 165-171.

Sheldrick GM 1997. SHELXL-97 - Program for Crystal Structure Refinement, University of Göttingen, Germany.

Travassos LR, Taborda CP, Colombo AL 2008. Treatment options for paracoccidioidomycosis and new strategies investigated. Expert Rev Anti Infect Ther 6: 251-262.

Vieira RP, Rocha L, Teixeira LR, Sinisterra RD, Coelho MM, Beraldo H 2010. Benzaldeído semicarbazona: um candidato a fármaco que alia simplicidade estrutural a um amplo perfil de atividades. Revista Virtual de Química 2: 2-9.

White TC, Marr KA, Bowden RA 1998. Clinical, cellular and molecular factors that contribute to antifungal drug resistance. Clin Microbiol Rev 11: 382-402.

Wills EA, Redinbo MR, Perfect JR, Poeta MD 2000. New potential targets for antifungal development. Expert Opin Ther Targets 4: 265-296.

Yang K, LeJeune J, Alsdorf D, Lu Bo, Shum CK, Liang S 2012. Global distribution of outbreaks of water-associated infectious diseases. PLoS Negl Trop Dis 6: e1483.

Zani C, Oliveira AB, Oliveira GG 1991. Furanonaphthoquinones from Tabebuia ochracea. Phytochemistry 30: 2379-2381. 